\title{
Hydrogen production in photosynthetic microbial mats in the Elkhorn Slough estuary, Monterey Bay
}

\author{
Luke C Burow $^{1,2}$, Dagmar Woebken ${ }^{1,2}$, Brad M Bebout ${ }^{2}$, Paul J McMurdie ${ }^{1}$, \\ Steven W Singer ${ }^{3}$, Jennifer Pett-Ridge ${ }^{4}$, Leslie Prufert-Bebout ${ }^{2}$, Alfred M Spormann ${ }^{1}$, \\ Peter K Weber ${ }^{4}$ and Tori M Hoehler ${ }^{2}$ \\ ${ }^{1}$ Department of Civil and Environmental Engineering, Stanford University, Stanford, CA, USA; ${ }^{2}$ Exobiology \\ Branch, NASA Ames Research Center, Moffett Field, CA, USA; ${ }^{3}$ Division of Earth Sciences, Lawrence \\ Berkeley National Laboratory, Berkeley, CA, USA and ${ }^{4}$ Division of Chemical Sciences, Lawrence Livermore \\ National Laboratory, Livermore, CA, USA
}

\begin{abstract}
Hydrogen $\left(\mathrm{H}_{2}\right)$ release from photosynthetic microbial mats has contributed to the chemical evolution of Earth and could potentially be a source of renewable $\mathrm{H}_{2}$ in the future. However, the taxonomy of $\mathrm{H}_{2}$-producing microorganisms (hydrogenogens) in these mats has not been previously determined. With combined biogeochemical and molecular studies of microbial mats collected from Elkhorn Slough, Monterey Bay, California, we characterized the mechanisms of $\mathrm{H}_{2}$ production and identified a dominant hydrogenogen. Net production of $\mathrm{H}_{2}$ was observed within the upper photosynthetic layer $(0-2 \mathrm{~mm})$ of the mats under dark and anoxic conditions. Pyrosequencing of rRNA gene libraries generated from this layer demonstrated the presence of 64 phyla, with Bacteriodetes, Cyanobacteria and Proteobacteria dominating the sequences. Sequencing of rRNA transcripts obtained from this layer demonstrated that Cyanobacteria dominated rRNA transcript pyrotag libraries. An OTU affiliated to Microcoleus spp. was the most abundant OTU in both rRNA gene and transcript libraries. Depriving mats of sunlight resulted in an order of magnitude decrease in subsequent nighttime $\mathrm{H}_{2}$ production, suggesting that newly fixed carbon is critical to $\mathrm{H}_{2}$ production. Suppression of nitrogen $\left(\mathrm{N}_{2}\right)$-fixation in the mats did not suppress $\mathrm{H}_{2}$ production, which indicates that co-metabolic production of $\mathrm{H}_{2}$ during $\mathrm{N}_{2}$-fixation is not an important contributor to $\mathrm{H}_{2}$ production. Concomitant production of organic acids is consistent with fermentation of recently produced photosynthate as the dominant mode of $\mathrm{H}_{2}$ production. Analysis of rRNA \% transcript: $\%$ gene ratios and $\mathrm{H}_{2}$-evolving bidirectional [NiFe] hydrogenase \% transcript: \% gene ratios indicated that Microcoelus spp. are dominant hydrogenogens in the Elkhorn Slough mats.
\end{abstract}

The ISME Journal (2012) 6, 863-874; doi:10.1038/ismej.2011.142; published online 20 October 2011

Subject Category: microbial ecology and functional diversity of natural habitats

Keywords: microbial mats; fermentation; hydrogen; hydrogenase; Microcoleus spp.; pyrotags

\section{Introduction}

Microbial mats are among the most phylogenetically and physiologically diverse ecosystems on Earth (Ley et al., 2006; Kunin et al., 2008; Bolhuis and Stal, 2011). These systems undergo daily cycling of redox potential, increasing as oxygenic phototrophs supersaturate the upper strata with oxygen during the day and then decreasing as the mats become completely anoxic at night. Although the role of mats in global carbon and oxygen cycling is acknowledged and well studied (Nisbet and Fowler, 1999; Des Marais, 2003), their $\mathrm{H}_{2}$ ecology has been underexplored.

Correspondence: LC Burow, Department of Civil and Environmental Engineering, Stanford University, 318 Campus Drive, E250, Stanford, CA 94305, USA.

E-mail: lukeburow@hotmail.com

Received 14 June 2011; revised 18 August 2011; accepted 19

August 2011; published online 20 October 2011
$\mathrm{H}_{2}$ release from microbial mats has likely been important for the chemical evolution of Earth, where its emission over long periods of geological time might be an important contributing factor to the oxidation of our atmosphere (Hoehler et al., 2001). Today, $\mathrm{H}_{2}$ is an important industrial chemical, where $10^{8} \mathrm{~m}^{3}$ (at $1 \mathrm{~atm}$ ) are sold annually in the US alone (Lee et al., 2010). Biological systems capable of producing industrially significant amounts of $\mathrm{H}_{2}$ have been an important focus of alternative energy research. Mat ecosystems could thus have a potential role as a renewable source of $\mathrm{H}_{2}$ in the future (Bender and Phillips, 2004). Knowledge of the metabolic processes that lead to $\mathrm{H}_{2}$ generation and the phylogenetic identity of associated $\mathrm{H}_{2}$-producing microorganisms (hydrogenogens) within highly complex microbial mat communities will be an important initial step towards realizing the potential of these systems as a viable $\mathrm{H}_{2}$ source. This knowledge will be useful in optimizing system parameters, 
such as light, carbon and nutrient concentrations, that enhance hydrogenogen activity and may facilitate future use of microbial mats as a commercial source of $\mathrm{H}_{2}$.

The activity of phototrophs and diazotrophs is well established in photosynthetic microbial mats (Des Marais, 2003) and both groups are capable of producing $\mathrm{H}_{2}$, either fermentatively or as a cometabolic product of $\mathrm{N}_{2}$-fixation (Bothe et al., 2010). Recent molecular ecology studies of microbial mats have focused on use of the $\mathrm{H}_{2}$-evolving bidirectional $[\mathrm{FeFe}]$ hydrogenase as a biomarker for investigating hydrogenogens in photosynthetic mats (Boyd et al., 2009, 2010). These studies infer that non-phototrophic, anaerobes are important hydrogenogens in mat ecosystems. However, the class of hydrogenases targeted and the assays used in these studies did not include $\mathrm{H}_{2}$-evolving bidirectional [NiFe] hydrogenases harbored by phototrophic microorganisms. To our knowledge, no studies have examined the diversity of $\mathrm{H}_{2}$-evolving bidirectional [NiFe] hydrogenases in microbial mats that may be active in phototrophic hydrogenogens that produce $\mathrm{H}_{2}$ by fermentative processes. Thus, our current understanding of the overall microbial ecology of $\mathrm{H}_{2}$ cycling in microbial mats remains an incomplete picture.

Previous work, which employed biogeochemical approaches has served to constrain several aspects of $\mathrm{H}_{2}$ cycling in microbial mats (Skyring et al., 1988, 1989; Hoehler et al., 2001). However, robust linkages between microorganisms and processes that generate $\mathrm{H}_{2}$ remain to be established and the taxonomic identity of principal hydrogenogens is unknown. In this study we determined the location of hydrogenogens in Elkhorn Slough mats, the relative importance of co-metabolic production of $\mathrm{H}_{2}$ during $\mathrm{N}_{2}$-fixation vs fermentation and phototrophic vs heterotrophic $\mathrm{H}_{2}$ production. In parallel we used pyrosequencing of SSU rRNA genes and transcripts and sequencing of $\mathrm{H}_{2}$-evolving bidirectional [NiFe] hydrogenase genes and transcripts to obtain evidence for the taxonomic identity of dominant hydrogenogens.

\section{Methods}

Field site sampling and short-term maintenance of mats in a greenhouse

Photosynthetic microbial mats were sampled from a tidal zone in the Elkhorn Slough estuary at Monterey Bay, California (Latitude $36.830{ }^{\circ} \mathrm{N}$, Longitude $-121.785{ }^{\circ} \mathrm{W}$ ) on November 9 , 2009. The samples measured $18 \times 23 \mathrm{~cm}^{2}$ and were $\sim 2 \mathrm{~cm}$ in depth. The samples were transported to the NASA Ames Research Center greenhouse within $1-2 \mathrm{~h}$ of collection from the slough. Upon arrival, mats were placed in acrylic aquaria transparent to ultraviolet radiation and covered with $4 \mathrm{l}$ of water $(\sim 3 \mathrm{~cm}$ of overlying water column) from the field site. The salinity of the field site water was $35 \%$ and had a $\mathrm{pH}$ of 8.0. Mats were incubated under natural solar irradiance and a regulated temperature $\left(\sim 19^{\circ} \mathrm{C}\right.$, in situ average) for up to 5 days, during which diel cycle experiments were carried out.

\section{Analysis of $\mathrm{H}_{2}$ and organic acids}

Replicate vials were prepared identically for each control or manipulation experiment as follows: small sub-cores (11 $\mathrm{mm}$ diameter, $15 \mathrm{~mm}$ depth or vertically sectioned for depth profile analyses) were cut from whole sections of intact microbial mat and placed in serum vials with $4 \mathrm{ml}$ of field site water. Serum vials were capped with butyl rubber stoppers. The $10.5 \mathrm{ml}$ headspace of the serum vials was left as air for light/daytime incubations and was thoroughly flushed with $\mathrm{N}_{2}$ (gas and liquid phase degassed) for dark/nighttime incubations. For $\mathrm{H}_{2}$ analysis, at least six replicate vials were sampled at each time point for each control or manipulation experiment. Organic acid production was analyzed in each of three replicates for each time point for each control or manipulation experiment. Manipulations included sectioning of microbial mat to identify the location of $\mathrm{H}_{2}$ production and suppression of diazotroph or phototroph (oxygenic and/or anoxygenic) activity to assess the roles of these microbial groups in $\mathrm{H}_{2}$ production. See supplementary methods for further information regarding $\mathrm{H}_{2}$ and organic acid analyses and details on how manipulation experiments were performed.

\section{Analysis of $\mathrm{N}_{2}$-fixation}

$\mathrm{N}_{2}$-fixation activity was determined using the acetylene reduction (ethylene production) assay in triplicate incubations for each time point for each control or manipulation experiment using standard methods (Stewart et al., 1967; Bebout et al., 1993).

\section{Statistical analysis}

To determine significant differences between $\mathrm{H}_{2}$ or organic acid production under control vs manipulated conditions, a one-way analysis of variance analysis was performed using the Tukey-HSD post hoc comparison within the JMP software package (v9; http://www.jmp.com/software/jmp9/). If a $P$-value of $<0.05$ was calculated between control and manipulated conditions, the difference was considered significant.

\section{Nucleic acid isolation and cDNA synthesis}

Microbial mat nucleic acids were isolated from at least three pooled mat cores, which were incubated in the same way as those analyzed for $\mathrm{H}_{2}$ and organic acid production. Mat cores were sampled periodically from serum vials and immediately transferred to $2 \mathrm{ml}$ tubes, flash frozen in liquid nitrogen and stored at $-80^{\circ} \mathrm{C}$. DNA and RNA were 
co-isolated from the upper photosynthetic layer $(0-2 \mathrm{~mm})$ of mat. DNA-free RNA was reverse transcribed to cDNA using random hexamers and a Superscript III first-strand synthesis kit (Invitrogen, Carlsbad, CA, USA). Further information regarding nucleic acid isolation, RNA purification and cDNA synthesis can be found in the supplementary methods.

Pyrotag sequencing of SSU rRNA genes and transcripts The V8 hypervariable region of the SSU rRNA gene was amplified from DNA (rRNA gene) or cDNA (rRNA transcript) templates using the universal primer pair 926f/1392r, including the titanium adaptor sequences and a five-base barcode on the reverse primer according to the previously published protocols for pyrotag sequencing (Engelbrektson et al., 2010). Amplicons were quality checked, trimmed to a 200-bp sequence length and clustered (97\% similarity) using PyroTagger (Kunin and Hugenholtz, 2010). Representative sequences from each cluster (OTU) were compared with the Greengenes NAST-aligned database (DeSantis et al., 2006) or the SILVA database (Pruesse et al., 2007) using PyroTagger (Kunin and Hugenholtz, 2010). Taxonomic affiliations of OTUs were further verified by querying the NCBI non-redundant nucleotide sequence databases (Altschul et al., 1990). If the best match was $100 \%$ identical over $200 \mathrm{bp}$, without multiple best matches to phylogenetically different taxa, then the OTU was conservatively assigned that taxonomic affiliation at the level of genus. If the OTU was $<100 \%$, but $\geqslant 97 \%$ identical its taxonomic assignment was conservatively set to the level of order. OTUs with $<97 \%$ identity matches were set to the level of phylum assigned by PyroTagger or if not assigned an identity by PyroTagger the OTU was unclassified (Kunin and Hugenholtz, 2010). Richness (Chao1 and ACE) and diversity (Simpson and Shannon) indices were calculated with the vegan package (v1.17-8) for R (v2.12; http://cran.r-project.org/web/packages/ vegan/index.html). Hughes et al., 2001 and Hill et al., 2003 provide further information and critical review of these indices application in microbial ecology.

Design of degenerate bidirectional [NiFe] hydrogenase specific primers, PCR amplification, cloning and sequencing

A database of bidirectional [NiFe] hydrogenase gene sequences from a range of Bacteria and Archaea was compiled from the NCBI non-redundant nucleotide sequence database (Altschul et al., 1990) and the Integrated Microbial Genomes database (Markowitz et al., 2006). Gene sequences were converted to protein sequences to screen for the presence of bidirectional [NiFe] hydrogenase signature motifs L1 Ex[APV]xxxxRxCG[IL]Cxx[AS]Hx[IL][ACS][AGS]
[AGNSV][KR][ATV]xD and L2 DPC[IL]SC[AS][AST] H[ASTV]x[AG]xx[APV] (PROSITE format; Vignais and Billoud, 2007). Sequences with $>2$ mismatches to signature motifs were not included in the database. The screened bidirectional [NiFe] hydrogenase gene sequences were aligned using MUSCLE (Edgar, 2004) and the resulting alignments checked manually in Geneious (v5.3, http://www.geneious. com). The database of aligned bidirectional [NiFe] hydrogenase gene sequences was queried against candidate degenerate primers using PRIMROSE to determine the number of mismatches between primers and templates and direct selection of the optimal degenerate primer pair (Ashelford et al., 2002). The optimal degenerate primer pair that targeted the broadest diversity of Cyanobacteria and Chloroflexales corresponded to positions 13-19 (IEGHAKI) and positions 167-173 (WAVPGGV) in the M. chthonoplastes PCC7420 bidirectional [NiFe] hydrogenase protein sequence. Genomic DNA (gDNA) or cDNA was used as the template to amplify a $\sim 480$-bp fragment of the bidirectional [NiFe] hydrogenase gene using the degenerate primers HoxH_F37 (5'-ATHGARGGHCAYGCBAAR AT-3') and HoxH_R518 (5'-ACNCCICCVGGNAYH GHCCA-3') using the following PCR cycling conditions; $1 \times 5 \mathrm{~min}, \quad 95{ }^{\circ} \mathrm{C}$ (enzyme activation); $35 \times 1 \mathrm{~min}, \quad 95^{\circ} \mathrm{C}$ (denature); $35 \times 1 \mathrm{~min}, \quad 56.5^{\circ} \mathrm{C}$ (anneal); $35 \times 1 \mathrm{~min}, 72^{\circ} \mathrm{C}$ (extend) and $1 \times 7 \mathrm{~min}$, $72{ }^{\circ} \mathrm{C}$ (final extension). The $25 \mu \mathrm{l}$ PCR reaction volume contained $12.5 \mu \mathrm{l}$ GoTaq green master mix (contains $1.5 \mathrm{mM} \mathrm{MgCl}_{2}$ and Taq enzyme; Promega, Madison, WI, USA), $8 \mu \mathrm{M}$ of each primer (HoxH_F37/HoxH_R518), $20 \mu \mathrm{g}$ bovine serum albumin and $1 \mu \mathrm{l}$ template (10 ng genomic DNA or $1 \mu \mathrm{l}$ of cDNA synthesis reaction). Positive and negative controls were also tested in PCR reactions (M. chthonoplastes PCC 7420 and Crocosphaera watsonii $\mathrm{WH}$ 8501, respectively) to evaluate the assay for efficiency and specificity. PCR products of the predicted size were excised from agarose gels after electrophoresis and purified using the Wizard SV gel and PCR clean-up system (Promega). Purified PCR product was ligated into the pCR2.1-topo vector (Invitrogen) and subsequently Sanger sequenced on a 3730xl DNA analyzer (Applied Biosystems, Foster City, CA, USA).

\section{Phylogenetic analysis of bidirectional [NiFe] \\ hydrogenase clone sequences}

Clone sequences were quality filtered, trimmed, translated to protein sequences, screened for L1 signature motif regions and aligned to a custom database of bidirectional [ $\mathrm{NiFe}$ ] hydrogenase protein sequences in Geneious (v5.3, http://www.geneious. com). Inferred hydrogenase amino-acid sequences were clustered at $97 \%$ similarity using CD-HIT (Huang et al., 2010) and representative sequences were queried against the NCBI non-redundant peptide sequence database (Altschul et al., 1990) 
to identify closest protein matches for phylogenetic analysis and tree building. Singletons were excluded from further analysis. Phylogenies were inferred using maximum-parsimony (PROTPARS; 1000 bootstraps) and maximum-likelihood (RAxML; PROTMIX rate distribution model; Dayhoff and WAG amino-acid substitution models; 1000 bootstraps) evolutionary models in ARB (Ludwig et al., 2004). Tree topologies from the different analyses were similar and the presented tree is based on a maximum-likelihood analysis, with bootstrap support of branch nodes indicated only when supported by all models. Representative clone sequences were deposited in GenBank (Accession numbers JF816258-JF816271).

\section{Results}

\section{$\mathrm{H}_{2}$ production}

A time-course incubation of vertically sectioned mat was conducted to assess net $\mathrm{H}_{2}$ production in space and time. $\mathrm{H}_{2}$ production was observed predominantly at night under anoxic conditions within the upper photosynthetic layer $(0-2 \mathrm{~mm})$ of the mat and was an order of magnitude greater than that produced in lower layers (Figure 1a). $\mathrm{H}_{2}$ produced in intact mat cores $(0-15 \mathrm{~mm})$ was similar to $\mathrm{H}_{2}$ produced in the sectioned mat cores $(0-2 \mathrm{~mm}$; upper phototrophic layer) when calculated per surface area (exposed top side surface only; Supplementary Figure S1). This data further supported the observation that $\mathrm{H}_{2}$ production is principally occurring within the upper layer.

Patterns of $\mathrm{H}_{2}$ and organic acid production observed in control and manipulation experiments reported here (Figure 1) were reproducible in mats sampled at other times during December-January 2008/2009 and August-October of 2009 (data not shown). However, the magnitude of $\mathrm{H}_{2}$ and organic acid production sometimes varied between diel cycle studies. This may have been due to community structure heterogeneity between different cores sampled from microbial mat pieces at different times or it may have been due to variable physiological states of hydrogenogens in the system.

\section{$\mathrm{H}_{2}$ production under phototroph suppressed conditions}

Manipulations of photosynthetic activity were performed to assess the role of different photosynthetic pathways and organisms in $\mathrm{H}_{2}$ production as explained below. In one set of experiments anoxygenic and oxygenic photosynthetic activity facilitated by photosystem (PSI) and photosytem II (PSII), respectively, was suppressed by depriving the mat of all light and thereby imposing continuously dark conditions over a complete diel cycle. In a second set of experiments performed under normal light conditions, 3-(3,4-dichlorophenyl)-1,1-dimethylurea (DCMU), a well-known inhibitor of PSII was added to inhibit oxygenic photosynthesis specifically. Inhibition of PSII was confirmed using PAM fluorometry (Supplementary Table S1) and was further supported anecdotally by the absence of oxygen bubbles, which normally appear at the surface of the mat (Supplementary Figure S2). Light deprivation and the subsequent cessation of all photosynthetic activity during the day reduced nighttime $\mathrm{H}_{2}$ production on the following night by an order of magnitude. However, specific and complete inhibition of oxygenic phototrophy did not significantly affect $\mathrm{H}_{2}$ production under dark, anoxic conditions (Figure 1b). Together these results indicate that prior-day activity of photosynthetic microorganisms is the source of reducing equivalents for $\mathrm{H}_{2}$ production and further suggest that anoxygenic phototrophy, facilitated by PSI, is fully capable of serving this function in Elkhorn Slough mats. However, these data alone do not distinguish between $\mathrm{H}_{2}$ production occurring predominantly by (i) obligate oxygenic phototrophs that are replaced by anoxygenic phototrophs under the conditions of our experimental manipulation, (ii) oxygenic phototrophs capable of facultative anoxygenic phototrophy, (iii) anoxygenic phototrophs; or (iv) a combination of (i)-(iii).

Production of $\mathrm{H}_{2}$ and organic acids under $\mathrm{N}_{2}$-fixation suppressed conditions

To evaluate the relative importance of co-metabolic production of $\mathrm{H}_{2}$ during $\mathrm{N}_{2}$-fixation vs fermentative $\mathrm{H}_{2}$ production, both of which are consistent with the observed pattern of $\mathrm{H}_{2}$ production in space and time, we suppressed $\mathrm{N}_{2}$-fixation. This was performed by addition of a combined nitrogen source $\left(\mathrm{NH}_{4} \mathrm{Cl}\right)$. Night time $\mathrm{N}_{2}$-fixation was completely suppressed when mats were incubated in the presence of $\mathrm{NH}_{4} \mathrm{Cl}$ (Supplementary Figure S3), but $\mathrm{H}_{2}$ production was not suppressed (Figure 1c). During the same nighttime period acetate, formate and propionate were produced with $\mathrm{H}_{2}$ under dark and anoxic conditions (expected products of fermentation; Figure 1d). Lactate, butyrate and valerate were not detected $(<200 \mathrm{nM})$. Organic acid accumulation was not significantly different when $\mathrm{N}_{2}$-fixation was suppressed under the same conditions (Figure 1d), with the exception of one time point (0:00). Together these results indicate that $\mathrm{N}_{2}$-fixation is a relatively insignificant contributor to $\mathrm{H}_{2}$ formation and suggest that fermentation is the dominant mechanism of production.

\section{SSU rRNA genes and transcripts}

To profile the identity and activity of microorganisms in Elkhorn Slough microbial mats, we compared rRNA gene and transcript pyrosequence tags from four different time points, including day and night samples (Table 1). For each time point DNA and RNA templates were co-isolated from the upper photosynthetic layer (0-2 $\mathrm{mm})$, as our biogeochemical 

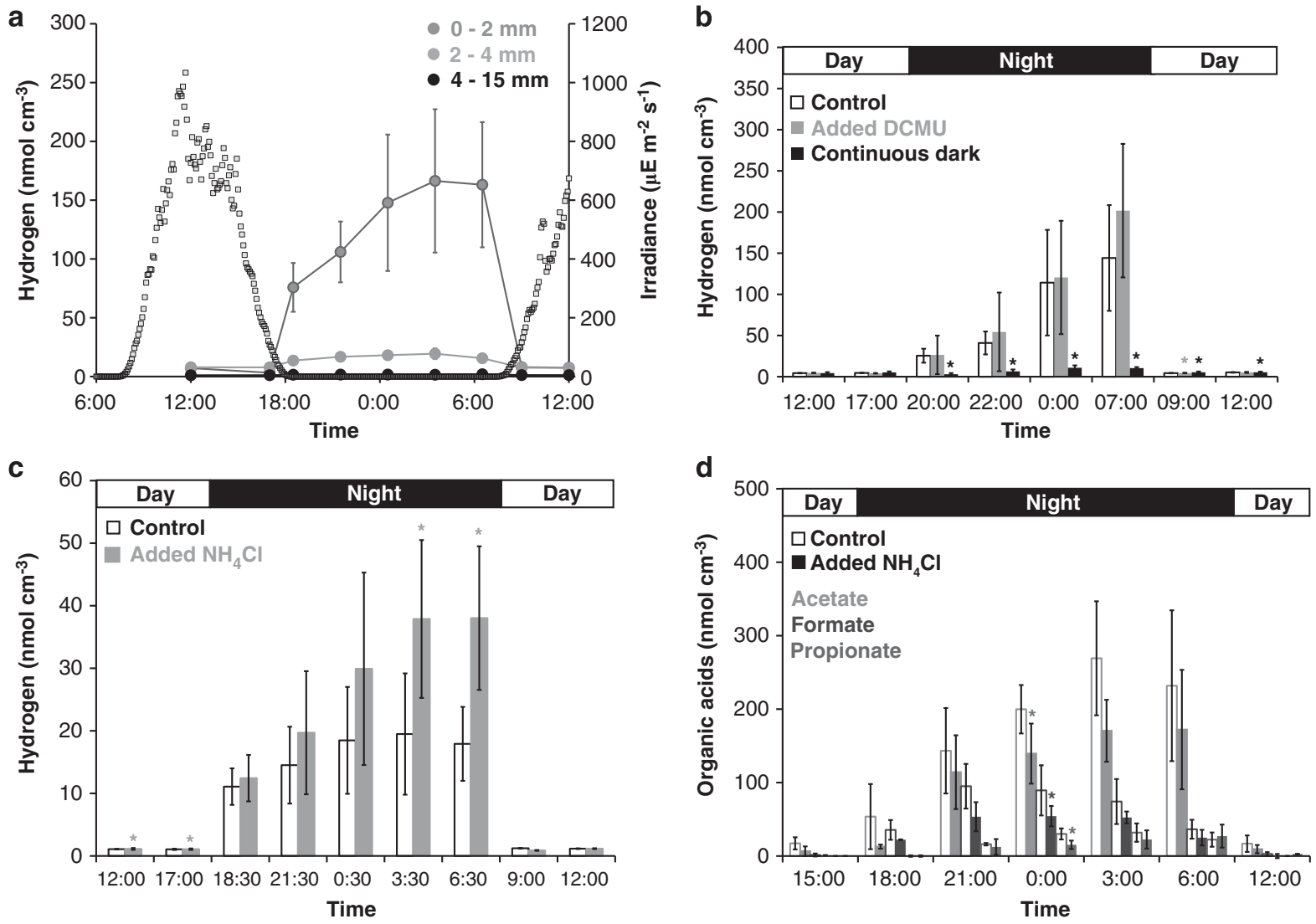

Figure 1 Diel production of $\mathrm{H}_{2}$ or organic acids under manipulated conditions in Elkhorn Slough mats. Mat core incubations in vials commenced at dawn with $\mathrm{H}_{2}$ and organic acids allowed to accumulate over a diel cycle with $\mathrm{N}_{2}$ flushing of the vial at the end of the day and night periods. Vials in which organic acids were measured were reset at dawn by replacement with fresh field site water (amended as appropriate for manipulated conditions). Vertical error bars indicate the s.d. of six replicates $\left(\mathrm{H}_{2}\right)$ or three replicates (organic acids). Asterisks denote significant differences between control and manipulated conditions $(P$ values $<0.05)$. (a) $\mathrm{H}_{2}$ production in different layers of microbial mat. Mat cores were sectioned at different depths, $0-2 \mathrm{~mm}, 2-4 \mathrm{~mm}$ and $4-15 \mathrm{~mm}$. Yellow squares denote natural solar irradiance. $\mu \mathrm{E}$, microeinsteins. (b) $\mathrm{H}_{2}$ production under control, DCMU $(20 \mu \mathrm{M})$ added and continuous dark conditions. (c) $\mathrm{H}_{2}$ production under control and $\mathrm{NH}_{4} \mathrm{Cl}(8.8 \mathrm{mM})$ added conditions. (d) Organic acid production under control and $\mathrm{NH}_{4} \mathrm{Cl}(8.8 \mathrm{mM})$ added conditions.

Table 1 Sampling times and statistics of rRNA gene and transcript pyrotag sequencing

\begin{tabular}{|c|c|c|c|c|c|c|}
\hline Library & Time and date & Pool & $\begin{array}{l}\text { Filtered reads } \\
(+) \text { singletons }\end{array}$ & $\begin{array}{l}\text { Filtered reads } \\
(-) \text { singletons }\end{array}$ & $\begin{array}{l}\text { OTUs }(97 \%)(+) \\
\text { singletons }\end{array}$ & $\begin{array}{l}\text { OTUs }(97 \%)(-) \\
\text { singletons }\end{array}$ \\
\hline No. 1 & Day, $1200,10 / 11 / 2009$ & DNA & 5796 & 5576 & 737 & 380 \\
\hline No. 2 & Day, 1200, 10/11/2009 & RNA & 5756 & 5641 & 486 & 233 \\
\hline No. 3 & Night, 0000, 11/11/2009 & DNA & 1191 & 1147 & 291 & 125 \\
\hline No. 4 & Night, 0000, 11/11/2009 & RNA & 5310 & 5230 & 357 & 166 \\
\hline No. 5 & Day, 1200, 12/11/2009 & DNA & 4487 & 4402 & 384 & 194 \\
\hline No. 6 & Day, $1200,12 / 11 / 2009$ & RNA & 4825 & 4780 & 242 & 121 \\
\hline No. 7 & Night, $0000,13 / 11 / 2009$ & DNA & 5573 & 5234 & 866 & 390 \\
\hline No. 8 & Night, $0000,13 / 11 / 2009$ & RNA & 4091 & 4038 & 275 & 121 \\
\hline
\end{tabular}

data demonstrated that $\mathrm{H}_{2}$ was predominantly produced within this layer.

Richness estimates calculated using Chao1 and ACE indices suggested that we had not exhaustively sequenced the upper photosynthetic layer of the microbial mat community (Table 2). Microbial diversity was consistently estimated to be highest in the rRNA gene libraries as determined using either the Simpson (inverse) or Shannon indices, with each rRNA gene library value higher than the value for the corresponding rRNA transcript library (Table 2).

Analysis of all four rRNA gene libraries $(n=17$ 047 sequences) revealed that 64 phyla/divisions across all three domains of life were present in the upper photosynthetic layer of Elkhorn Slough microbial mats (Supplementary Table S2). Abundant phyla/divisions included, Bacteriodetes (29\%), 
Table 2 Richness and diversity estimates of OTUs (97\% similarity)

\begin{tabular}{|c|c|c|c|c|c|}
\hline \multirow[t]{2}{*}{ Library } & \multicolumn{3}{|c|}{ OTU richness ${ }^{\mathrm{a}}$} & \multicolumn{2}{|c|}{ OTU diversity ${ }^{\mathrm{b}}$} \\
\hline & Observed & Chao1 & $A C E$ & Simpson $^{\mathrm{c}}$ & Shannon \\
\hline No. 1 (Day $1^{\mathrm{d}}$, DNA) & 737 & $1309( \pm 86)$ & $1334( \pm 22)$ & 52.84 & 5.08 \\
\hline No. 2 (Day 1, RNA) & 486 & $880( \pm 70)$ & $952( \pm 19)$ & 5.30 & 3.15 \\
\hline No. 3 (Night $1^{\text {d }}$, DNA) & 291 & $633( \pm 81)$ & $616( \pm 16)$ & 29.55 & 4.52 \\
\hline No. 4 (Night 1, RNA) & 357 & $645( \pm 59)$ & $681( \pm 15)$ & 3.88 & 2.63 \\
\hline No. 5 (Day $2^{\mathrm{d}}$, DNA) & 384 & $723( \pm 72)$ & $715( \pm 16)$ & 14.10 & 3.77 \\
\hline No. 6 (Day 2, RNA) & 242 & $469( \pm 62)$ & $433( \pm 13)$ & 3.38 & 2.18 \\
\hline No. 7 (Night $2^{\text {d, DNA) }}$ & 866 & $1679( \pm 107)$ & $1813( \pm 28)$ & 35.20 & 4.96 \\
\hline No. 8 (Night 2, RNA) & 275 & $543( \pm 63)$ & $613( \pm 16)$ & 3.93 & 2.50 \\
\hline
\end{tabular}

${ }^{a}$ Chao1 and ACE (abundance-based coverage estimators) indices are non-parametric estimators of species (OTU) richness (total number of different OTUs in a given sample).

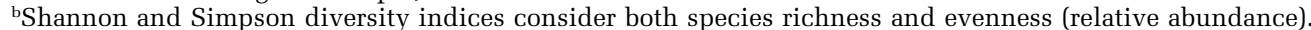

${ }^{\mathrm{c}}$ Inverse simpson values are reported.

${ }^{\mathrm{d} D a y} 1$ is 1200 hours, on 10 November, 2009; Night 1 is 0000 hours, on 11 November, 2009; Day 2 is 1200 hours, on 12 November, 2009 ; Night 2 is 0000 hours, on 13 November, 2009.

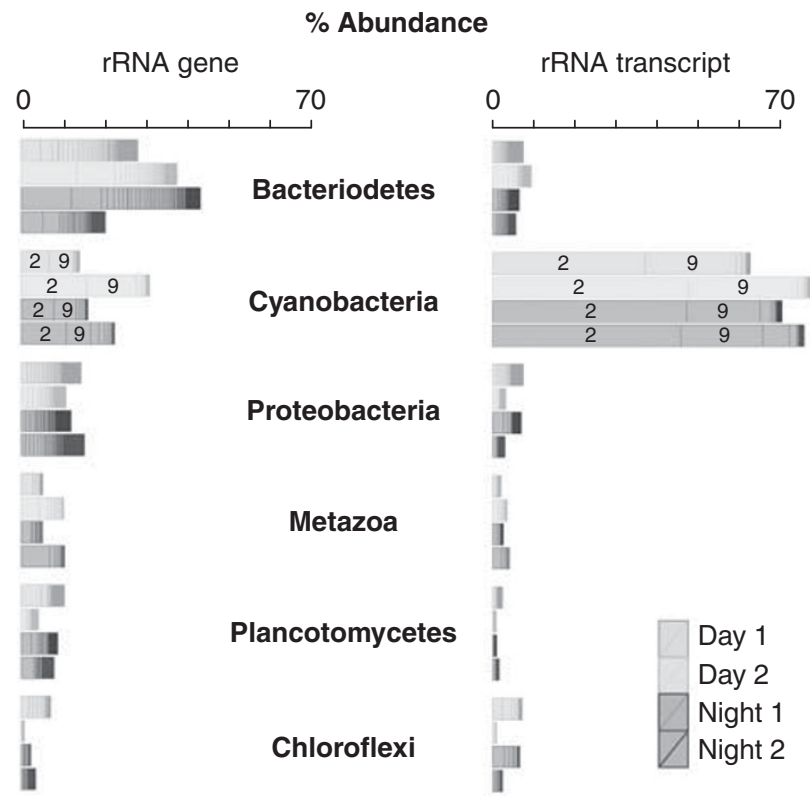

Figure 2 Ranked barplot of the six most abundant phyla of the rRNA gene (left) and rRNA transcript (right) libraries. Day 1 is 12:00 on 10 November, 2009, Day 2 is 12:00 on 11 November, 2009, Night 1 is 0:00 on 11 November, 2009 and Night 2 is 0:00 on 13 November, 2009. OTUs within the same phyla are stacked in order of relative abundance and separated graphically into segments. The most abundant OTUs no. 2, Microcoleus spp. and no. 9, Cyanobacteria) are labeled according to their (arbitrary) OTU identification number assigned during PyroTagger clustering.

Cyanobacteria (22\%) and Proteobacteria (14\%) (average of four libraries; Figure 2). A lower diversity of phyla/divisions were recovered from the upper photosynthetic layer of all four rRNA transcript libraries ( $n=19982$ sequences), with 49 phyla/divisions represented (Supplementary Table S3). Cyanobacteria dominated these libraries, representing $71 \%$ of all reads (average of four libraries; Figure 2). The rRNA transcript libraries were dominated by Microcoleus spp. affiliated OTU 2
(Library no. 2, Day 1, 37\%; Library no. 4, Night 1, 47\%; Library no. 6, Day 2, 48\%; Library no. 8, Night 2, 46\%; Figure 2) and Cyanobacteria affiliated OTU 9 (Library no. 2, Day 1, 22\%; Library no. 4, Night 1 , 18\%; Library no. 6, Day 2, 27\%; Library no. 8, Night 2, 20\%; Figure 2). These OTUs are likely important members of the active microbial mat community during the day and also at night.

Relative activity of microbial populations was inferred at the transcript level from the ratio of the fraction of tags in the rRNA transcript library (active microorganisms) to those in the paired rRNA gene library (active + inactive microorganisms) for a given time point. OTUs were considered relatively active if the \% rRNA transcripts recovered was greater than the \% rRNA genes recovered that is, \% rRNA transcripts:\% rRNA genes ratio $>1$ (Rodriguez-Blanco et al., 2009; Jones and Lennon, 2010). These ratios may give additional insight into active microorganisms beyond those that we previously identified from our rRNA transcript libraries (the 'abundant and active' OTUs 2 and 9) and identify those organisms that are relatively 'rare and active' that are not obvious from examination of rRNA transcript libraries alone. We were specifically interested in detecting microorganisms correlated with $\mathrm{H}_{2}$ production and thus we report in Table 3 only those OTUs that were most relatively active at night and present in all our nighttime libraries. Microcoleus spp. (OTU 2) had the highest nighttime $\%$ transcript:\% gene ratios of all OTUs analyzed (present in all libraries), 6.0 (Nov/11/2009) and 4.2 (Nov/13/2009). An OTU (225) with the second highest nighttime ratios was affiliated with the Desulfobacterales (Table 3). Bacteria within this order are exclusively sulfate-reducing bacteria (SRB) and these microorganisms may also be $\mathrm{H}_{2}$-consumers (hydrogenotrophs; Widell, 1987). The most relatively active nighttime OTUs present in all nighttime libraries were predominantly microbial groups within either the Cyanobacteria or 
Table 3 rRNA \% transcript :\% gene ratios of the most relatively active OTUs observed in all nighttime pyrotag libraries

\begin{tabular}{|c|c|c|c|c|c|c|c|}
\hline$O T U^{\mathrm{a}}$ & Most related sequences ${ }^{\mathrm{b}}$ & $\begin{array}{l}\text { Accession } \\
\text { number }\end{array}$ & Identities $^{\mathrm{c}}$ & $E$-value & $\begin{array}{l}\text { OTU taxonomic } \\
\text { affiliation }^{\mathrm{e}}\end{array}$ & $\begin{array}{l}\text { Ratio }^{\mathrm{f}} \text { night } 1 \\
\text { 11/11/2009 }\end{array}$ & $\begin{array}{l}\text { Ratiof night 2, } \\
\text { 13/11/2009 }\end{array}$ \\
\hline \multirow[t]{2}{*}{2} & Microcoleus chthonoplastes & AM709630 & $200 / 200$ & $6 e-97$ & Microcoleus spp. & 6.0 & 4.2 \\
\hline & Microcoleus chthonoplastes & GQ402023 & $200 / 200$ & $6 e-97$ & & & \\
\hline \multirow[t]{2}{*}{225} & Desulfococcus sp. & EF442980 & $194 / 200$ & $9 e-89$ & Desulfobacterales & 5.5 & 2.6 \\
\hline & Desulfococcus multivorans & AF418173 & $194 / 200$ & $9 e-89$ & & & \\
\hline \multirow[t]{2}{*}{5} & Leptolyngbya fragilis & HQ832925 & $198 / 200$ & $3 e-94$ & Oscillatoriales & 4.1 & 3.2 \\
\hline & Coral bacterium clone & FJ203604 & $193 / 200$ & $4 e-87$ & & & \\
\hline \multirow[t]{2}{*}{9} & Mat bacterium clone & EU246323 & $200 / 200$ & $7 e-97$ & Cyanobacteria & 3.3 & 3.3 \\
\hline & Phormidium cf. formosum ${ }^{\mathrm{b}}$ & EU196640 & $190 / 200$ & $2 e-83$ & & & \\
\hline \multirow[t]{2}{*}{31} & Mat chloroflexales clone & AJ308496 & $200 / 200$ & $7 e-97$ & Chloroflexales & 4.8 & 1.5 \\
\hline & Oscillochloris sp. ${ }^{\mathrm{b}}$ & AF149018 & $188 / 200$ & $2 \mathrm{e}-78$ & & & \\
\hline \multirow[t]{2}{*}{387} & Microbialite nematoda clone & GQ483712 & $200 / 200$ & $7 e-97$ & Nematoda & 2.1 & 3.7 \\
\hline & Eumonhystera cf. simplex ${ }^{\mathrm{b}}$ & AY284692 & $177 / 200$ & $6 e-66$ & & & \\
\hline \multirow[t]{2}{*}{379} & Wetland cytophagales clone & FJ516772 & $188 / 200$ & $1 e-80$ & Bacteriodetes & 1.6 & 3.8 \\
\hline & Aquiflexum balticum ${ }^{\mathrm{b}}$ & NR025634 & $186 / 200$ & $7 e-78$ & & & \\
\hline \multirow[t]{2}{*}{1176} & Mat chloroflexi clone & DQ329977 & $199 / 200$ & $3 e-95$ & Chloroflexi & 1.9 & 2.9 \\
\hline & Oscillochloris sp. ${ }^{\mathrm{b}}$ & AF149018 & $178 / 200$ & $5 e-67$ & & & \\
\hline
\end{tabular}

${ }^{\mathrm{a} O T U}$ identification number is arbitrary and wa designated by PyroTagger.

bThe NCBI non-redundant nucleotide sequence database was queried to identify closest matches to OTU sequences; closest pure culture match where a given OTU has its closest matches to only uncultured clone sequences.

'BLASTN uses an identity matrix for nucleotide comparisons, see http://www.ncbi.nlm.nih.gov/BLAST/; total length of query was 200 bp.

${ }^{\mathrm{d}} E$-value or expect value describes the significance of the match between two sequences, see http://www.ncbi.nlm.nih.gov/BLAST/.

${ }^{\text {e}}$ For OTU taxonomic affiliation designation see methods (Pyrotag sequencing of SSU rRNA genes and transcripts).

${ }^{\mathrm{f}} \mathrm{rRNA} \%$ transcript:\% gene ratios were calculated for sequences recovered from DNA or cDNA template-based libraries constructed from Night 1 (0000 hours) on 11 November, 2009 or Night 2 (0000 hours) on 13 November, 2009 samples by dividing the percentage abundance of pyrotags in the rRNA transcript library by the percentage abundance in the rRNA gene library.

Chloroflexi. These data correlate with our biogeochemical data and generally support the hypothesis that Cyanobacteria, including Microcoleus spp. (oxygenic phototrophs) and/or members of the Chloroflexi (anoxygenic phototrophs) are hydrogenogens in Elkhorn Slough mats.

\section{$\mathrm{H}_{2}$-evolving bidirectional [NiFe] hydrogenase genes and transcripts}

$\mathrm{H}_{2}$-evolving bidirectional [NiFe] hydrogenases are found in a diversity of Cyanobacteria, Chloroflexi and Proteobacteria (also other Bacteria and Archaea) and are the only known hydrogenases in these taxonomic groups capable of evolving $\mathrm{H}_{2}$ via fermentation (Tamagnini et al., 2007; Vignais and Billoud, 2007). Thus, genes encoding for these enzymes represent useful biomarkers for evaluating the diversity of hydrogenogens in photosynthetic microbial mats. [NiFe] hydrogenases are quite diverse (Vignais and Billoud, 2007) and therefore it is impossible to design degenerate primers that capture the entire diversity that may be present in highly complex ecosystems such as microbial mats. However, as our biogeochemical and pyrotag sequencing data indicated that the important hydrogenogens in this system are potentially members of the Cyanobacteria and Chloroflexales, we focused on amplifying bidirectional [NiFe] hydrogenases from these two groups, for which it was possible to design a single PCR-based assay.

Amplicons were generated that spanned the L1 signature motif region of the large subunit of the bidirectional [NiFe] hydrogenase. The primer pair HoxH_F37/HoxH_R518 designed in this study generated an amplicon of $\sim 480 \mathrm{bp}$, shorter than the bidirectional $[\mathrm{NiFe}]$ hydrogenase-specific primer pair HoxHf/HoxHr that produces an 1190-bp amplicon (Barz et al., 2010). However, HoxH_F37 and HoxH_R518 have substantially fewer primertemplate mismatches to publicly available bidirectional [NiFe] hydrogenase genes than the bidirectional [NiFe] hydrogenase-specific primer pair HoxHf and HoxHr (Supplementary Table S4). Of the 39 publicly available Cyanobacteria or Chloroflexales bidirectional [NiFe] hydrogenases 38 had $\leqslant 2$ mismatches to HoxH_F37/HoxH_R518 compared with 9 of 39 for HoxHf/HoxHr, indicating that HoxH_F37/HoxH_R518 targets a larger portion of bidirectional [NiFe] hydrogenases from Cyanobacteria and Chloroflexales. Analysis of a selection of uptake [NiFe] hydrogenases showed that all had $\geqslant 3$ primer-template mismatches to HoxH_F37/ HoxH_R518 (Supplementary Table S4). Amplicons of the expected size were generated from a selection of Cyanobacteria strains and one Chloroflexales strain that have a bidirectional [NiFe] hydrogenase, but these amplicons were not generated from Crocosphaera watsonii WH 8501, a cyanobacterium that does not have a bidirectional [NiFe] hydrogenase but has an uptake [NiFe] hydrogenase (Supplementary Table S5).

A total of 205 bidirectional [NiFe] hydrogenase gene and transcript fragments were amplified from DNA (91 clones) and RNA (cDNA; 114 clones) templates obtained from the upper photosynthetic 
Table $4 \%$ transcript:\% gene ratios of bidirectional [NiFe] hydrogenase sequence clusters

\begin{tabular}{|c|c|c|c|c|c|c|}
\hline $\begin{array}{l}\text { Sequence } \\
\text { cluster }\end{array}$ & Most related sequences ${ }^{\mathrm{a}}$ & $\begin{array}{c}\text { Accession } \\
\text { number }\end{array}$ & $\% I D$ & $\begin{array}{l}\text { Transcript } \\
\text { clones }\end{array}$ & Gene $^{\mathrm{c}}$ clones & Ratio $^{\mathrm{d}}$ \\
\hline \multirow[t]{2}{*}{ HoxH1 } & Microcoleus chthonoplastes PCC7420 & ZP_05027024 & 98 & $70(61 \%)$ & $28(31 \%)$ & $2.0(61 \%: 31 \%)$ \\
\hline & Arthrospira maxima CS328 & ZP_03273562 & 92 & & & \\
\hline \multirow[t]{2}{*}{ HoxH2 } & Microcoleus chthonoplastes PCC7420 & ZP_05027024 & 96 & $17(15 \%)$ & $3(3 \%)$ & $4.5(15 \%: 31 \%)$ \\
\hline & Cyanothece sp. PCC7822 & YP_003888687 & 93 & & & \\
\hline \multirow[t]{2}{*}{ HoxH3 } & Arthrospira platensis FACHB439 & AAQ63960 & 87 & $2(2 \%)$ & $0(0 \%)$ & - $^{\mathrm{e}} \mathrm{r}-\mathrm{c}$ \\
\hline & Arthrospira maxima CS328 & ZP_03273562 & 87 & & & \\
\hline \multirow[t]{2}{*}{ HoxH4 } & Cyanothece sp. PCC8802 & YP_003135898 & 70 & $10(9 \%)$ & $44(48 \%)$ & $0.2(9 \%: 48 \%)$ \\
\hline & Cyanothece sp. PCC8801 & YP_002370357 & 70 & & & \\
\hline \multirow[t]{2}{*}{ HoxH5 } & Roseiflexus castenholzii DSM13941 & YP_001431482 & 73 & $0(0 \%)$ & $4(4 \%)$ & - \\
\hline & Anaerolinea thermophila UNI1 & YP_004173889 & 73 & & & \\
\hline \multirow[t]{2}{*}{ HoxH6 } & Anabaena variabilis ATCC29413 & YP_325153 & 68 & $0(0 \%)$ & $6(7 \%)$ & - \\
\hline & Synechococcus sp. PCC7335 & ZP_05039794 & 68 & & & \\
\hline \multirow[t]{2}{*}{ HoxH7 } & Cyanothece sp. PCC8801 & YP_002370357 & 68 & $3(3 \%)$ & $1(1 \%)$ & $2.4(3 \%: 1 \%)$ \\
\hline & Solibacter usitatus Ellin6076 & YP_826256 & 68 & & & \\
\hline \multirow[t]{2}{*}{ HoxH8 } & Roseiflexus sp. RS1 & YP_001277847 & 80 & 0 & $2(2 \%)$ & - \\
\hline & Nostoc sp. PCC7120 & NP_484809 & 80 & & & \\
\hline \multirow[t]{2}{*}{ HoxH9 } & Desulfurispirillum indicum S5 & YP_004113284 & 78 & $10(9 \%)$ & $0(0 \%)$ & - \\
\hline & Nostoc sp. PCC7120 & NP_484809 & 75 & & & \\
\hline
\end{tabular}

aAmino-acid sequences inferred from nucleotide sequences.

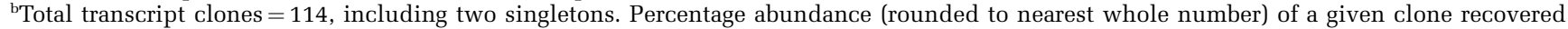
from the transcript library is denoted in parenthesis.

${ }^{\mathrm{c}}$ Total gene clones $=91$, including three singletons. Percentage abundance (rounded to nearest whole number) of a given clone recovered from the gene library is denoted in parenthesis.

d\% transcript:\% gene ratios calculated by dividing percentage abundance of transcript clones by the percentage abundance of gene clones.

${ }^{\mathrm{e}}$ Ratio was not calculated as numerator or denominator was $0 \%$.

layer (0-2 mm) of Elkhorn Slough mats under dark anoxic conditions at 0000 hours, on 11 November, 2009. The gene and transcript fragments formed nine distinct clusters (including five singleton clusters) at the $97 \%$ similarity threshold (Table 4 ; Figure 3). The majority of the sequences were affiliated with M. chthonoplastes PCC7420 (HoxH1 and HoxH2 clusters). The HoxH1 cluster represented $31 \%$ of gene clones and $61 \%$ of transcript clones (98\% identity; >65\% bootstrap support for branch point) and the HoxH2 cluster represented $3 \%$ of gene clones and $15 \%$ of transcript clones (96\% identity; $>50 \%$ bootstrap support for branch point). Another highly represented cluster, HoxH4 (48\% of gene clones; $9 \%$ of transcript clones), was most closely related to Cyanothece sp. PCC8802 (70\% identity; unresolved branch point). Clusters HoxH1 and HoxH2 were relatively active, with a \% transcript:\% gene ratio $>1$, whereas HoxH4 was relatively inactive with a $\%$ transcript: $\%$ gene ratio $<1$.

\section{Discussion}

Analyses of rRNA and $\mathrm{H}_{2}$-evolving bidirectional [NiFe] hydrogenase genes and transcripts combined with biogeochemical measurements across a range of manipulations strongly suggest that fermentation of stored photosynthate by Microcoleus spp. is a major source of $\mathrm{H}_{2}$ in Elkhorn Slough mats.

$\mathrm{H}_{2}$ production occurred predominantly in the upper photosynthetic layer $(0-2 \mathrm{~mm})$ of Elkhorn
Slough mats. Similar results have been reported in other photosynthetic mats from Guerrero Negro, Mexico (Hoehler et al., 2001), suggesting that quantitatively important hydrogenogens are active in the upper layer of geographically diverse mats. Elkhorn Slough mats also harbored SRB (Desulfobacterales; Table 3), a group known to be actively reducing sulfate over the full diel cycle in photosynthetic microbial mats (Canfield and Des Marais, 1991). These microorganisms include hydrogenotrophs (Widdel, 1987) and thus $\mathrm{H}_{2}$ production observed in our experiments is likely a measurement of net $\mathrm{H}_{2}$ production. Our observations cannot rule out that enhanced $\mathrm{H}_{2}$ consumption in deeper layers accounts for the lower net $\mathrm{H}_{2}$ production relative to the upper photosynthetic layer. Indeed, we anticipate that more stable physico-chemical conditions within the permanently dark, anoxic portion of the mat should allow for the development of closer associations between hydrogenogens and hydrogenotrophs, and thus a lower net efflux of $\mathrm{H}_{2}$ than in the highly dynamic upper phototrophic layer. However, we hypothesize that the observed rates of $\mathrm{H}_{2}$ and organic acid production are unlikely to be sustained in lower aphotic layers, which lack daily photosynthetic replenishment of the fixed carbon pool and therefore have a discrete reservoir of carbon that would be rapidly depleted. Further investigation of hydrogenotrophs is needed to better understand the complete $\mathrm{H}_{2}$ cycle and controls on net $\mathrm{H}_{2}$ production in microbial mats.

Previous research of microbial mats from Shark Bay, Australia had concluded that co-metabolic 


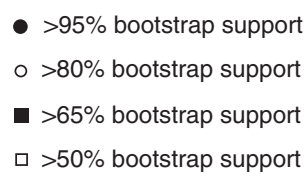

Geminocystis herdmanii PCC6308 Gloeocapsa alpicola str. CALU743 Synechocystis PCC6803

L Microcystis aeruginosa NIES84 - Cyanothece sp. PCC7424

Cyanothece sp. PCC7828 Cyanothece sp. CCY0110

ㄴ Cyanothece sp. ATCC51142

Cyanothece sp. PCC8801 Cyanothece sp. PCC8802

Microcoleus chthonoplastes PCC7420

- HoxH1 (70 cDNA: 28 DNA)

- HoxH2 (17 cDNA: 3 DNA)

L Lyngbya majuscula CCAP1446/4

L Lyngbya sp. PCC8106

Arthrospira platensis NIES39

Arthrospira platensis FACHB349

Spirulina subsala FACHB351

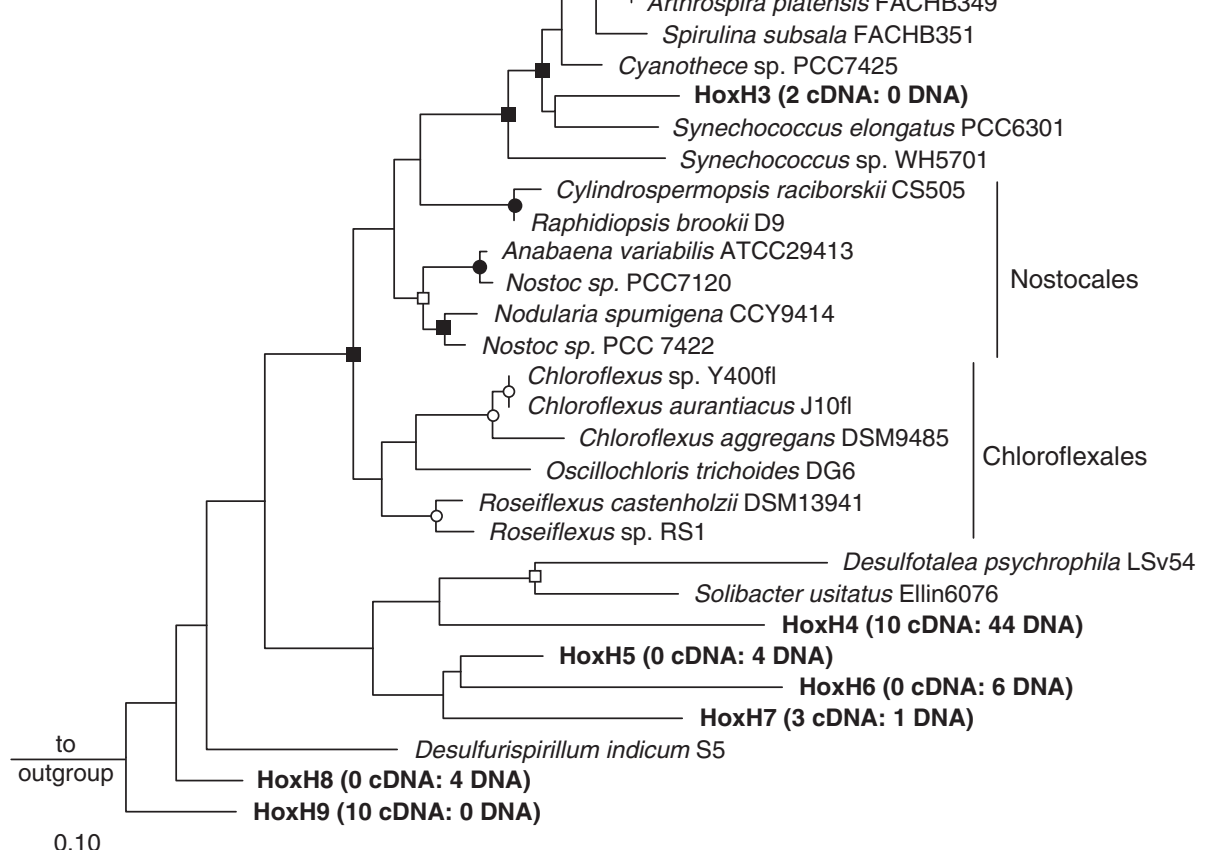

0.10

Figure 3 Maximum-likelihood phylogenetic tree of bidirectional [NiFe] hydrogenases. Branch points supported by all phylogenetic analyses (maximum likelihood using Dayhoff or WAG amino-acid correction and maximum parsimony evolutionary models) and their bootstrap support are denoted. The bar represents 0.1 changes per amino acid and the outgroup was Methanococcus voltae A3 HoxH.

production of $\mathrm{H}_{2}$ during $\mathrm{N}_{2}$-fixation could be an important contributor to net $\mathrm{H}_{2}$ production as $\mathrm{N}_{2}$ fixation was observed to occur contemporaneously with $\mathrm{H}_{2}$ production (Skyring et al., 1989). Similar patterns of $\mathrm{N}_{2}$-fixation and $\mathrm{H}_{2}$ production were observed in mats from Elkhorn Slough. However, further examination of the role of $\mathrm{N}_{2}$-fixation in $\mathrm{H}_{2}$ production using $\mathrm{N}_{2}$-fixation suppression experiments indicated that $\mathrm{H}_{2}$-production is independent of $\mathrm{N}_{2}$-fixation and most likely fermentative due to the simultaneous production of organic acids (expected fermentation products) under dark and anoxic conditions.

Inhibition of phototrophic activity generally or oxygenic phototrophy specifically, by respectively, depriving the microbial mats of solar irradiance or by inhibiting with DCMU suggested that phototrophs were important contributors to the $\mathrm{H}_{2}$ production observed during the subsequent night- time period. However, biogeochemical data alone did not provide evidence to identify the type of phototroph or the taxonomic identity of microorganisms producing $\mathrm{H}_{2}$.

Our analysis of rRNA genes and transcripts demonstrated that Cyanobacteria, specifically Microcoleus spp. were important members of the active microbial community. We obtained results similar to an investigation of photosynthetic mats from Guerrero Negro, Mexico by Ley and colleagues (2006). In both studies, Cyanobacteria dominated the active microbial communities as determined by rRNA transcript analysis despite being substantially less significant within the total (active + inactive) community as determined by rRNA gene analysis. These observations underscore the need to investigate both the presence and activity of microorganisms in complex microbial ecosystems to gain a better understanding of their likely metabolic importance. 
872

Some cyanobacterial strains isolated in pure culture from microbial mats are capable of fermentative $\mathrm{H}_{2}$ production from stored photosynthate, including glycogen (Stal and Moezelaar, 1997). No studies have been carried out on true Microcoleus sp. isolates to ascertain their capabilities of producing $\mathrm{H}_{2}$ (Garcia-Pichel et al., 1996; Moezelaar et al., 1996; Bolhuis et al., 2010). However, recent analysis of publicly available cyanobacterial genomes have shown that all Cyanobacteria (including M. chthonoplastes PCC7420) harboring a bidirectional [NiFe] hydrogenase also harbor a pyruvate:flavodoxin/ ferredoxin oxidoreductase, leading to speculation that the bidirectional [NiFe] hydrogenase is used to shunt electrons (as $\mathrm{H}_{2}$ ) via a pyruvate:flavodoxin/ ferredoxin oxidoreductase-like enzyme during fermentation (Barz et al., 2010). $\mathrm{H}_{2}$-evolving bidirectional $[\mathrm{NiFe}]$ hydrogenase clone libraries constructed from the upper photosynthetic layer of Elkhorn Slough mats using degenerate primers designed to equally target many Cyanobacteria and Chloroflexales were dominated by sequence clusters most closely affiliated with $M$. chthonoplastes PCC7420 (Figure 3). Overrepresentation of hydrogenases in the transcript library for clusters most closely affiliated with M. chthonoplastes PCC7420 (Table 4) provides further evidence that Microcoleus spp. are the main hydrogenogens in Elkhorn Slough mats.

Data obtained in this study indicate that anoxygenic phototrophy can drive $\mathrm{H}_{2}$ production in microbial mats. Facultative anoxygenic phototrophy in Cyanobacteria, including Microcoleus sp. has been reported (Garlick et al., 1977; Cohen et al., 1986; De Wit et al., 1988). However, misidentification of cyanobacterial strains as Microcoleus sp., including 'strain 11' used by de Wit and colleagues (1988) has been documented (Garcia-Pichel et al., 1996; Bolhuis et al., 2010) and thus it is unclear if Microcoleus spp. are capable of anoxygenic phototrophy. The capability of Microcoleus spp. to switch between oxygenic and anoxygenic phototrophy might be important to their survival and proliferation in microbial mats where sulfurous compounds can be prevalent and inhibit PSII activity (Jorgensen et al., 1986). Alternatively, anoxygenic phototrophic Chloroflexi strains may have a role in $\mathrm{H}_{2}$ production. Analysis of nighttime rRNA gene and transcript libraries revealed that OTU 31 affiliated with Chloroflexales and OTU 1176 affiliated with Chloroflexi were overrepresented in the rRNA transcript libraries. These OTUs had \% transcript:\% gene ratios $>1$ in both nighttime samples (Table 3 ), indicating that they were consistently relatively active when $\mathrm{H}_{2}$ production was pronounced. Cloning of $\mathrm{H}_{2}$-evolving bidirectional [NiFe] hydrogenases did not indicate that Chloroflexales bidirectional [NiFe] hydrogenases were expressed. It should be noted that although degenerate primers were designed to amplify bidirectional [NiFe] hydrogenases from a diversity of Cyanobacteria and
Chloroflexales, a relatively high number of mismatches $(\geqslant 2)$ between both forward and reverse primers to the bidirectional [NiFe] hydrogenase gene was determined for one of the Chloroflexales members, Oscillochloris trichoides DG6 (Supplementary Table S4). Thus, it is possible that Oscillochloris-like spp. or other as yet unknown Chloroflexales may contribute to the observed $\mathrm{H}_{2}$ produced in Elkhorn Slough mats without being represented in the hydrogenase gene and transcript libraries. In this regard it is noteworthy that the closest pure culture match to OTUs 31 and 1176, was Oscillochloris sp. BM (Table 3).

Although we do not rule out a role for Chloroflexales in $\mathrm{H}_{2}$ production, analysis of rRNA pyrotags and bidirectional [NiFe] hydrogenases indicates that Cyanobacteria, including Microcoleus spp., were relatively more active than Chloroflexales. Also, the dominance of Microcoleus spp. within the active fraction of the microbial community in the $\mathrm{H}_{2}$ producing layer suggests that the contribution of microorganisms other than Cyanobacteria to $\mathrm{H}_{2}$ production is likely minimal. Together, these biogeochemical data, manipulations and molecular data demonstrate that Microcoleus spp. are dominant hydrogenogens in Elkhorn Slough mats.

\section{Acknowledgements}

We thank Michael Kubo, Adrienne Frisbee, Angela Detweiler and Erich Fleming for technical support. We thank Tijana Glavina del Rio, Susannah Tringe and Stephanie Malfatti of the Joint Genome Institute for assistance obtaining and analyzing amplicon pyrosequencing. Funding was provided by the U.S. Department of Energy (DOE) Genomic Sciences Program under contract SCW1039. Work at LLNL was performed under the auspices of the U.S. Department of Energy at Lawrence Livermore National Laboratory under Contract DE-AC5207NA27344. Work at LBNL was performed under the auspices of the U.S. Department of Energy at Lawrence Berkeley National Laboratory under Contract DE-AC0205CH11231. DW was supported by the German Research Foundation (Deutsche Forschungsgemeinschaft).

\section{References}

Altschul SF, Gish W, Miller W, Myers EW, Lipman DJ. (1990). Basic local alignment search tool. J Mol Biol 215: 403-410.

Ashelford KE, Weightman AJ, Fry JC. (2002). PRIMROSE: a computer program for generating and estimating the phylogenetic range of $16 \mathrm{~S}$ rRNA oligonucleotide probes and primers in conjunction with the RDP-II database. Nucleic Acids Res 30: 3481-3489.

Barz M, Beimgraben C, Staller T, Germer F, Opitz F, Marquardt C et al. (2010). Distribution analysis of hydrogenases in surface waters of marine and freshwater environments. PLOS ONE 5: e13846. 
Bebout BM, Fitzpatrick MW, Paerl HW. (1993). Identification of the sources of energy for nitrogen fixation and physiological characterization of nitrogen-fixing members of a marine microbial mat community. Appl Environ Microbiol 59: 1495-1503.

Bender J, Phillips P. (2004). Microbial mats for multiple applications in aquaculture and bioremediation. Bioresour Technol 94: 229-238.

Bolhuis H, Severin I, Confurius-Guns V, Wollenzien UI, Stal LJ. (2010). Horizontal transfer of the nitrogen fixation gene cluster in the cyanobacterium Microcoleus chthonoplastes. ISME J 4: 121-130.

Bolhuis H, Stal LJ. (2011). Analysis of bacterial and archaeal diversity in coastal microbial mats using massive parallel 16S rRNA gene tag sequencing. ISME J; e-pub ahead of print 5 May 2011; doi:10.1038/ ismej.2011.52.

Bothe H, Schmitz O, Yates MG, Newton WE. (2010). Nitrogen fixation and hydrogen metabolism in cyanobacteria. Microbiol Mol Biol R 74: 529.

Boyd ES, Hamilton TL, Spear JR, Lavin M, Peters JW. (2010). [FeFe]-hydrogenase in yellowstone national park: evidence for dispersal limitation and phylogenetic niche conservatism. ISME J 4: 1485-1495.

Boyd ES, Spear JR, Peters JW. (2009). [FeFe] hydrogenase genetic diversity provides insight into molecular adaptation in a saline microbial mat community. Appl Environ Microbiol 75: 4620-4623.

Canfield DE, Des Marais DJ. (1991). Aerobic sulfate reduction in microbial mats. Science 251: 1471-1473.

Cohen Y, Jorgensen BB, Revsbech NP, Poplawski R. (1986). Adaptation to hydrogen sulfide of oxygenic and anoxygenic photosynthesis among cyanobacteria. Appl Environ Microbiol 51: 398-407.

De Wit R, van Boekel WHM, van Gemerden H. (1988). Growth of the cyanobacterium Microcoleus chthonoplastes on sulfide. FEMS Microbiol Ecol 53: 203-209.

Des Marais DJ. (2003). Biogeochemistry of hypersaline microbial mats illustrates the dynamics of modern microbial ecosystems and the early evolution of the biosphere. Biol Bull 204: 160-167.

DeSantis TZ, Hugenholtz P, Larsen N, Rojas M, Brodie EL, Keller K et al. (2006). Greengenes, a chimera-checked $16 \mathrm{~S}$ rRNA gene database and workbench compatible with ARB. Appl Environ Microbiol 72: 5069-5072.

Edgar RC. (2004). MUSCLE: multiple sequence alignment with high accuracy and high throughput. Nucleic Acids Res 32: 1792-1797.

Engelbrektson A, Kunin V, Wrighton KC, Zvenigorodsky $\mathrm{N}$, Chen F, Ochman $\mathrm{H}$ et al. (2010). Experimental factors affecting PCR-based estimates of microbial species richness and evenness. ISME J 4: 642-647.

Garcia-Pichel F, Prufert-Bebout L, Muyzer G. (1996). Phenotypic and phylogenetic analyses show Microcoleus chthonoplastes to be a cosmopolitan cyanobacterium. Appl Environ Microbiol 62: 3284-3291.

Garlick S, Oren A, Padan E. (1977). Occurence of facultative anoxygenic photosynthesis among filamentous and unicellular cyanobacteria. J Bacteriol 129: 623-629.

Hill TC, Walsh KA, Harris JA, Moffett BF. (2003). Using ecological diversity measures with bacterial communities. FEMS Microbiol Ecol 43: 1-11.

Hoehler TM, Bebout BM, Des Marais DJ. (2001). The role of microbial mats in the production of reduced gases on the early Earth. Nature 412: 324-327.
Huang Y, Niu B, Gao Y, Fu L, Li W. (2010). CD-HIT Suite: a web server for clustering and comparing biological sequences. Bioinformatics 26: 680-682.

Hughes JB, Hellmann JJ, Ricketts TH, Bohannan BJ. (2001). Counting the uncountable: statistical approaches to estimating microbial diversity. Appl Environ Microbiol 67: 4399-4406.

Jones SE, Lennon JT. (2010). Dormancy contributes to the maintenance of microbial diversity. Proc Natl Acad Sci USA 107: 5881-5886.

Jorgensen BB, Cohen Y, Revsbech NP. (1986). Transition from anoxygenic to oxygenic photosynthesis in a Microcoleus chthonoplastes cyanobacterial mat. Appl Environ Microbiol 51: 408-417.

Kunin V, Hugenholtz P. (2010). PyroTagger: A fast, accurate pipeline for analysis of rRNA amplicon pyrosequence data. Open J 1: e1.

Kunin V, Raes J, Harris J, Spear J, Walker J, Ivanova N et al. (2008). Millimeter-scale genetic gradients and community-level molecular convergence in a hypersaline microbial mat. Mol Syst Biol 4: e198.

Lee H, Vermaas WFJ, Rittmann BE. (2010). Biological hydrogen production: prospects and challenges. Trends Biotechnol 28: 262-271.

Ley RE, Harris JK, Wilcox J, Spear JR, Miller SR, Bebout $\mathrm{BM}$ et al. (2006). Unexpected diversity and complexity of the guerrero negro hypersaline microbial mat. Appl Environ Microbiol 72: 3685-3695.

Ludwig W, Strunk O, Westram R, Richter L, Meier H. (2004). ARB: a software environment for sequence data. Nucleic Acids Res 32: 1363-1371.

Markowitz VM, Korzeniewski F, Palaniappan K, Szeto E, Werner G, Padki A et al. (2006). The integrated microbial genomes (IMG) system. Nucleic Acids Res 34: D344-D348.

Moezelaar R, Bijvank SM, Stal LJ. (1996). Fermentation and sulfur reduction in the mat-building cyanobacterium Microcoleus chthonoplastes. Appl Environ Microbiol 62: 1752-1758.

Nisbet EG, Fowler CMR. (1999). Archaean metabolic evolution of microbial mats. Proc $R$ Soc Lond B Biol Sci 266: 2375-2382.

Pruesse E, Quast C, Knittel K, Fuchs BM, Ludwig W, Peplies J et al. (2007). SILVA: a comprehensive online resource for quality checked and aligned ribosomal RNA sequence data compatible with ARB. Nucleic Acids Res 35: 7188-7196.

Rodriguez-Blanco A, Ghiglione JF, Catala P, Casamayor EO, Lebaron P. (2009). Spatial comparison of total vs active bacterial populations by coupling genetic fingerprinting and clone library analyses in the NW Mediterranean Sea. FEMS Microbiol Ecol 67: 30-42.

Skyring GW, Lynch RM, Smith GD. (1988). Acetylene reduction and hydrogen metabolism by a cyanobacterial/sulfate-reducing bacterial mat ecosystem. Geomicrobiol J 6: 25-31.

Skyring GW, Lynch RM, Smith GD. (1989). Quantitative relationship between carbon, hydrogen and sulfur metabolism in cyanobacterial mats. In Cohen Y, Rosenberg E (eds), Microbial mats: Physiological ecology of benthic microbial communities. American Society for Microbiology: Washington, DC, pp. 170-179.

Stal LJ, Moezelaar R. (1997). Fermentation in cyanobacteria. FEMS Microbiol Rev 21: 179-211. 
Stewart WD, Fitzgerald GP, Burris RH. (1967). In situ studies on $\mathrm{N}_{2}$-fixation using the acetylene reduction technique. Proc Natl Acad Sci USA 58: 2071-2078.

Tamagnini P, Leitao E, Oliveira P, Ferreira D, Pinto F, Harris DJ et al. (2007). Cyanobacterial hydrogenases: diversity, regulation and applications. FEMS Microbiol Rev 31: 692-720.
Vignais PM, Billoud B. (2007). Occurrence, classification, and biological function of hydrogenases: an overview. Chem Rev 107: 4206-4272.

Widdel F. (1987). New types of acetate-oxidizing, sulfatereducing Desulfobacter species, $D$ hydrogenophilus sp. nov, D latus sp. Nov and D curvatus sp. nov. Arch Microbiol 148: 286-291.

Supplementary Information accompanies the paper on The ISME Journal website (http://www.nature.com/ismej) 